\title{
Fabrication of Chlorophyll-Incorporated Nanogels for Potential Applications in Photothermal Cancer Therapy
}

\author{
Ray Chang, Chin-Feng Hsu, and Wei-Bor Tsai*(i) \\ Department of Chemical Engineering, National Taiwan University, No. 1, Sec. 4, Roosevelt Rd., Taipei 106, Taiwan
}

Supporting Information

ABSTRACT: Nanogels have been widely used in biomedical applications, such as carriers for hyperthermia cancer treatment, drug delivery, and imaging. Owing to the enhanced permeability and retention effect, nanogels have shown a great potential in cancer therapy. In this study, sodium copper chlorophyllin (SCC), a low cytotoxicity and biodegradable photothermal agent, was copolymerized with a nanogel of $\mathrm{N}$ [3-(dimethylamino)propyl]methacrylamide. The nanogels could produce heat under exposure to a green laser with a $532 \mathrm{~nm}$ wavelength. The positively charged nature of the nanogels enhanced the endocytosis of the nanogels. The cell mortality was greatly enhanced with the treatment of the SCCcontaining nanogels and green light illumination. Our results suggest the potential of SCC-containing nanogels in photothermal cancer therapy.

\section{INTRODUCTION}

Cancer remains one of the most frequent causes of mortality in developed countries, and the incidence of cancer keeps elevating because of increasing aged population. ${ }^{1}$ Traditional cancer treatments, such as surgery, radiotherapy, and chemotherapy, still have some shortcomings, such as the risks of killing normal cells or destroying the immune systems of the patients. $^{2}$ Owing to the advantage of minimal invasiveness, hyperthermia therapy has been developed as an alternative technique for cancer treatment. ${ }^{3,4}$ Hyperthermia cancer therapy is based on localized heating, which in turn raises the temperature around the targeted tumor tissues to $41-45$ ${ }^{\circ} \mathrm{C}$. ${ }^{5}$ As cancerous cells are more vulnerable to elevated temperatures than normal cells, hyperthermia may kill cancer cells with a minimal damage to adjacent normal tissues. One type of hyperthermia therapies is photothermal therapy (PTT), using electromagnetic radiation to induce heat from a photothermal agent. ${ }^{6}$ The efficacy of hyperthermia induced by photothermal agents has been shown to be higher than those of traditional hyperthermia methods. ${ }^{7}$ Many researchers have attempted to transfer the photothermal agents into cancerous tissues via nanocarriers. ${ }^{8}$ Because of their excellent stability, easy preparation, and high designability, nanogels with chemically cross-linked networks have been widely used as polymeric nanovesicles for therapeutic agents. ${ }^{9,10}$ Incorporation of photothermal agents to a nanogel would be beneficial for in vivo applications because it would improve the cellular uptake of photothermal agents and thus enhance the efficiency of hyperthermia. ${ }^{11,12}$

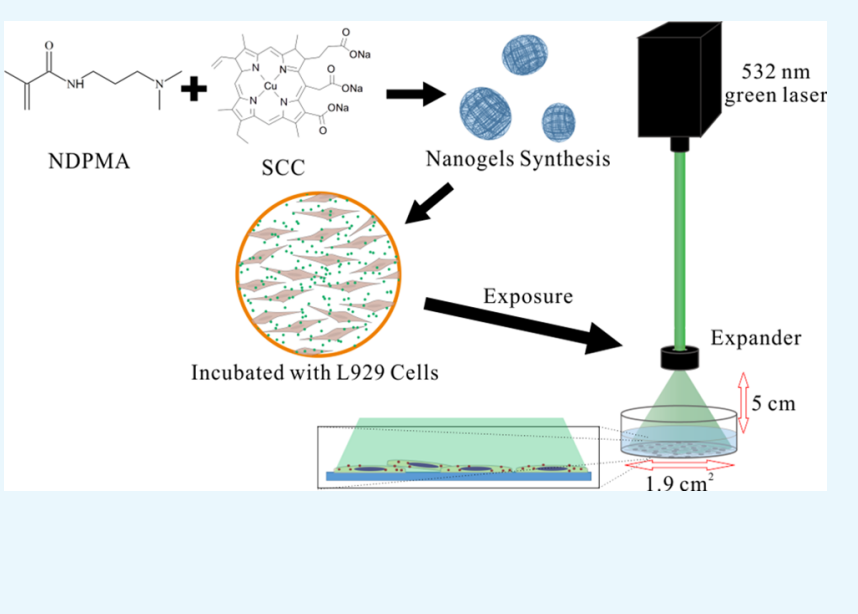

The most used electromagnetic radiation for PTT is nearinfrared (NIR) light, ${ }^{7,13}$ which can penetrate into deeper biological soft tissues. ${ }^{14}$ One disadvantage associated with the NIR light is that the absorption of NIR light by water is higher than that of the light within the spectrum between 300 and 800 $\mathrm{nm}$ wavelength. ${ }^{15}$ Visible light, though with a lower tissue penetration depth, has been used in certain medical procedures $^{16}$ and might be applied to PTT. For example, green light $(495-570 \mathrm{~nm})$ has been applied for decades in several clinical treatments, including ocular disorders and benign prostatic hyperplasia. ${ }^{17,18}$ Several recent studies demonstrated that green light can be absorbed by metallic nanoparticles (NPs), leading to excitations in the form of localized surface plasmon resonance and driving a photothermal effect. ${ }^{19-21}$ Therefore, we would like to study the potential application of green light in PTT.

The objective of this work is to synthesize a polymeric nanogel containing green light-activated photothermal agents and then to evaluate its potential application in PTT. Porphyrin-containing molecules, such as protoporphyrin IX, tetra(meso-hydroxy)phenyl chlorin, and sodium copper chlorophyllin (SCC), absorb green light and generate heat. Among the porphyrin molecules, SCC, a low-cytotoxicity and biodegradable photosensitizer with high photothermal conversion efficiency, ${ }^{22,23}$ was chosen as the photothermal agent in this study. A nanogel composed of $N$-[3-(dimethylamino)-

Received: July 17, 2018

Accepted: November 16, 2018

Published: November 27, 2018 
propyl]methacrylamide (NDPMA) and SCC was synthesized. The positively charged NDPMA with tertiary amines could facilitate the nanogel to access cells via electrostatic attractions with the negatively charged cell membrane. ${ }^{24}$ The photothermal effect of SCC-containing nanogels via green laser illumination was studied for its cell-killing efficacy in vitro.

\section{RESULTS AND DISCUSSION}

2.1. Cytotoxicity of SCC. The cytotoxicity of SCC was first evaluated to determine whether or not it is suitable as a photothermal agent. The $\mathrm{IC}_{50}$ value of SCC was determined as $0.63 \mathrm{mM}$ (Figure 1). When the SCC concentration was below

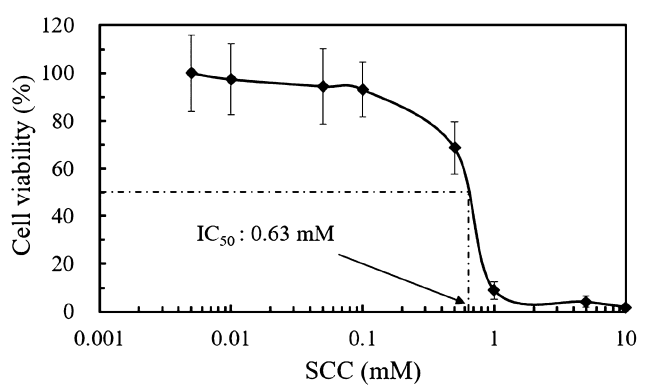

Figure 1. Cytotoxicity assay of SCC. The values are presented as mean \pm standard deviation $(n=5)$.

$0.10 \mathrm{mM}$, the cell viability was beyond $90 \%$. Therefore, if the amount of SCC in the nanogels is less than $0.10 \mathrm{mM}$, the nanogel should be considered to exhibit low cytotoxicity.

2.2. Fabrication and Characterization of SCC-Containing Nanogels. Two types of nanogels were synthesized, polyNDPMA (abbreviated as NDP) and poly(NDPMA-coSCC) (abbreviated as NDPC). The nanogels with the SCC weight ratio of $10 \%$ or $20 \%$ were named as $\mathrm{NDPC}_{10}$ or $\mathrm{NDPC}_{20}$, respectively. First of all, we tried to use proton nuclear magnetic resonance $\left({ }^{1} \mathrm{H} \mathrm{NMR}\right)$ to characterize the incorporation of SCC during the polymerization of NDPMA. However, the incorporation of SCC seems to interfere with the ${ }^{1} \mathrm{H}$ NMR signals (Figure S1). The intensities of the NMR signals of $\mathrm{NDPC}_{20}$ were much weaker than those of NDP and $\mathrm{NDPC}_{10}$. Several studies suggested that $\mathrm{Cu}(\mathrm{II})$, a paramagnetic ion, broadens or weakens the nuclear resonance via paramagnetic relaxation effects. ${ }^{25-27}$ We suspect that the magnetic properties of $\mathrm{Cu}$ ions in SCC interfere with the ${ }^{1} \mathrm{H}$ NMR signals. Therefore, ${ }^{1} \mathrm{H}$ NMR is not suitable for the quantitative analysis of SCC in the nanogels.

In this study, we used two methods for the determination of SCC contents in the nanogels. First, the contents of SCC in the nanogels were determined according to its absorbance at $405 \mathrm{~nm}$, based on a calibration curve of free SCC (Figure S2). The amounts of SCC in NDPC were roughly 9.8 and $19.7 \mathrm{wt}$ $\%$, with the addition of 7 and $21 \mathrm{mg}$ SCC, respectively. Herein, $\mathrm{NDP}, \mathrm{NDPC}_{10}$, and $\mathrm{NDPC}_{20}$ denote the nanogels containing $0,9.8$, and 19.7 wt \% SCC, respectively. Second, the content of $\mathrm{Cu}$ (II) in the SCC-containing nanogels was evaluated by inductively coupled plasma atomic emission spectroscopy (ICP-AES). The concentrations of copper ions were $\sim 3.3$ and $8.73 \mu \mathrm{g} / \mathrm{mg}$ nanogels (equivalent to 8.2 and $21.7 \mathrm{wt} \% \mathrm{SCC}$ ) in $\mathrm{NDPC}_{10}$ and $\mathrm{NDPC}_{20}$, respectively. The SCC contents determined by the two methods are close.

The average diameters of NDP, $\mathrm{NDPC}_{10}$, and $\mathrm{NDPC}_{20}$, determined by dynamic light scattering (DLS), were around
$254 \pm 75,215 \pm 90$, and $308 \pm 120 \mathrm{~nm}$, respectively (Figure 2). The size distributions of $\mathrm{NDPC}_{10}$ and $\mathrm{NDPC}_{20}$ were

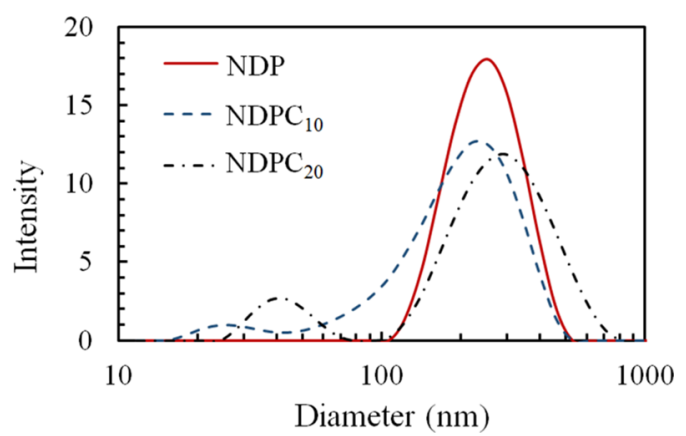

Figure 2. DLS analysis of different nanogels.

broader than that of NDP. Beside the major peaks around 215-308 nm, minor peaks below $100 \mathrm{~nm}$ appeared in the spectra of $\mathrm{NDPC}_{10}$ and $\mathrm{NDPC}_{20}$, suggesting that SCC interferes with the polymerization of NDPMA, resulting in a broader size distribution. The zeta potential measurement shows that $\mathrm{NDP}, \mathrm{NDPC}_{10}$, and $\mathrm{NDPC}_{20}$ exhibited positive surface charges at $43.1,49.2$, and $38.9 \mathrm{mV}$, respectively, resulting from the tertiary amines of NDPMA. It should be noted that the nanogels with different sizes may have different SCC compositions, which will affect their photothermal properties, endocytosis, and cytotoxicity. However, the separation of nanogels with different sizes is tedious; so, we used the mixtures in the preliminary study.

2.3. Cytotoxicity of the Nanogels. In this study, a positively charged monomer, NDPMA, was used for the preparation of nanogels because it is well-known that macromolecules containing positive charges tend to be endocytosed. However, positively charged macromolecules are notorious for their cytotoxicity. ${ }^{28}$ As this is a proof-ofconcept study, NDPMA was used for the testing.

MTS analysis indicates that the $\mathrm{IC}_{50}$ values of NDP, $\mathrm{NDPC}_{10}$, and $\mathrm{NDPC}_{20}$ were estimated to be about 145, 140, and $125 \mu \mathrm{g} / \mathrm{mL}$, respectively (Figure 3 ). The results demonstrate the cytotoxicity of the NDPMA-based nanogels, which is the reason for the $2 \mathrm{~h}$, instead of $24 \mathrm{~h}$, incubation time in this cytotoxicity test. Thus, we picked a concentration below the $\mathrm{IC}_{50}$ value of $100 \mu \mathrm{g} / \mathrm{mL}$ to test the photothermal response

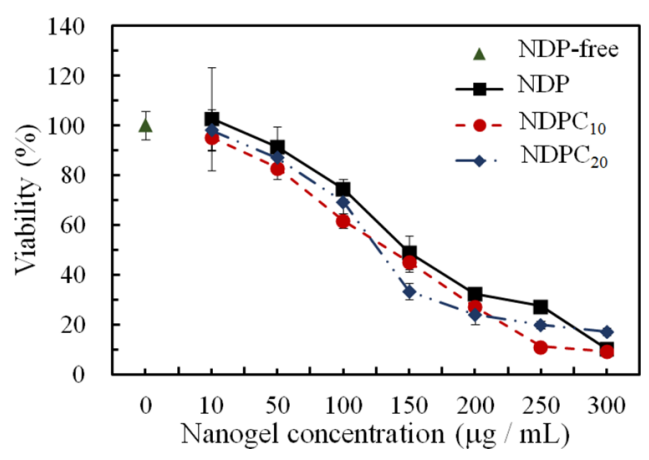

Figure 3. Cytotoxicity study of L929 cells that were cultured in the culture medium containing various amounts of nanogels for $2 \mathrm{~h}$. The cell viability was determined using an MTS assay. The data are represented as mean \pm standard deviation, $n=3$. 
and evaluate whether or not the concentration is sufficient for hyperthermia treatment.

2.4. Photothermal Property of the Nanogels. The photothermal property of SCC-NDP was estimated from the temperature increase of the nanogel solution after the illumination of green laser $(532 \mathrm{~nm})$ for a certain period. Water does not absorb green light; so, the temperature rise was ignored or limited, especially at the laser intensity below $3 \mathrm{~W}$ (Figure 4A). The illumination of $4 \mathrm{~W}$ green laser for $4 \mathrm{~min}$

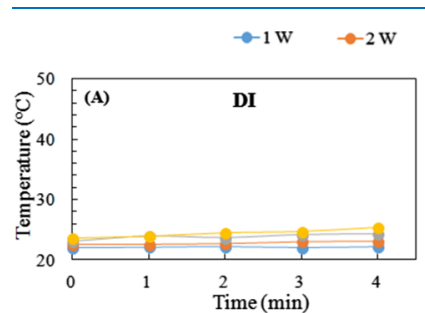

$$
\rightarrow-3 \mathrm{w} \quad \rightarrow-4 \mathrm{w}
$$
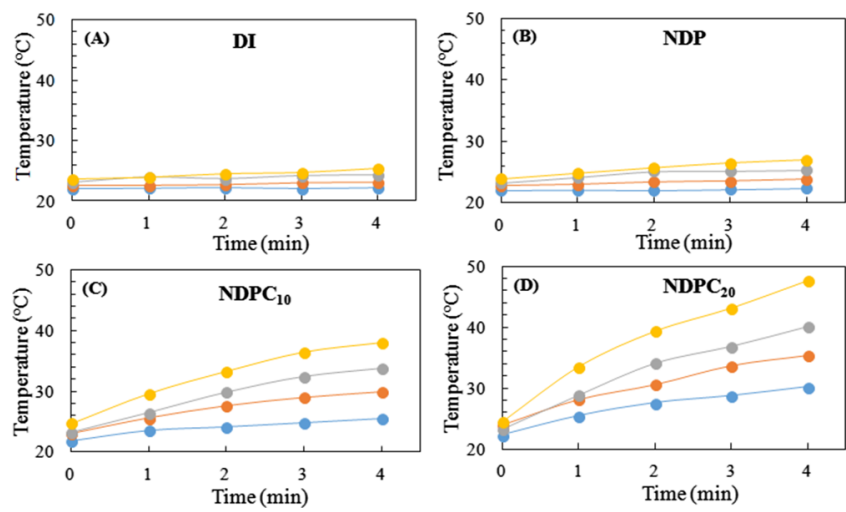

Figure 4. Heating diagrams of (A) DI water, (B) NDP nanogels, and (C,D) nanogels with different SCC contents (NDPC) after illumination by green light at $532 \mathrm{~nm}$. The nanogel concentration was $100 \mu \mathrm{g} / \mathrm{mL}$.

merely raised the water temperature by $\sim 2{ }^{\circ} \mathrm{C}$. Similarly, NDP did not raise the water temperature after green laser illumination (Figure 4B). By contrast, the nanogels containing SCC absorb green laser energy and convert into heat to raise the water temperature. The extent of temperature rise is increased with the SCC contents at the same laser intensity. The water temperature was raised by $\sim 11$ or $\sim 17{ }^{\circ} \mathrm{C}$ for $\mathrm{NDPC}_{10}$ or $\mathrm{NDPC}_{20}$, after a 4 min illumination of $3 \mathrm{~W}$ green laser (Figure 4C,D). The results reveal that NDPC generates heat efficiently, leading to a significant temperature elevation, which is sufficient for PTT. The measured temperature is the average temperature of the solution; so, the temperature at the sites of SCC-containing nanogels should be even higher. As the water temperature rise does not occur by the illumination of green laser below $3 \mathrm{~W}$, the laser intensity was applied for the subsequent photothermal experiments.

2.5. Cellular Uptake of the Nanogels. Our proposed mechanism for the photothermal effect is that the SCCcontaining nanogels first enter a cell and then generate heat to kill the cell upon illumination of green laser (Scheme 1). Thus, it is important to verify the cellular uptake of NDPCs.

First, the cellular uptake of NDPC nanogels was evaluated by the determination of $\mathrm{Cu}$ contents in the cells. After the L929 cells were cultured with $100 \mu \mathrm{g} / \mathrm{mL}$ of $\mathrm{NDPC}_{10}$ or $\mathrm{NDPC}_{20}$, the cells contain about 0.526 or $0.772 \mathrm{ppm} \mathrm{Cu}(\mathrm{II})$, respectively. However, the cells incubated with NDP without SCC also contained $0.346 \mathrm{ppm} \mathrm{Cu}(\mathrm{II})$, which should come from the intrinsic copper ions in the cells. For example, cytochrome $c$ oxidase, a transmembrane protein complex found in mitochondria, contains two copper centers. ${ }^{29,30}$ After being subtracted from the intrinsic $\mathrm{Cu}(\mathrm{II})$, the NDPCassociated copper could be used for the estimation of cellular
Scheme 1. Schematic Illustration of the Experimental Procedure

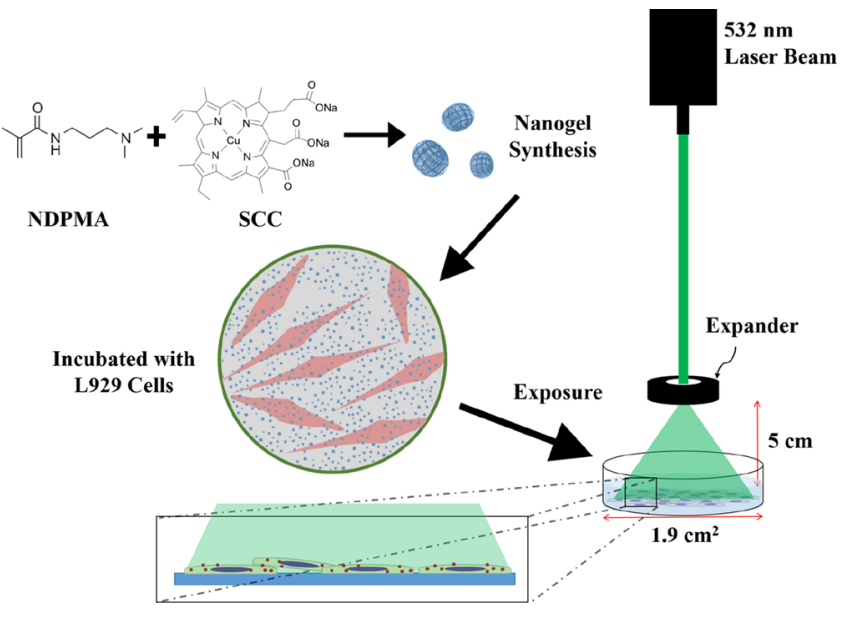

uptake of NDPC nanogels. We estimated that each cell engulfed $10 \mathrm{pg}$ of $\mathrm{NDPC}_{10}$ or $9.3 \mathrm{pg}$ of $\mathrm{NDPC}_{20}$.

Because the high level of cellular intrinsic $\mathrm{Cu}$ ions might interfere with the determination of the amount of engulfed NDPs, the cellular uptake of NDPs was also evaluated via the incorporation of gold NPs (AuNPs). AuNP-NDP nanogels were imaged using transmission electron microscopy (TEM) (Figure S3), showing that AuNP is encapsulated in the nanogel. The average diameter of AuNP-NDP was around $190 \mathrm{~nm}$, determined by DLS (Figure S4).

The contents of cell-internalized AuNP-NDP nanogels were extracted from the cells and the amount of $\mathrm{Au}$ was determined using ICP-AES. The total amount of cellinternalized gold from AuNP-NDPs was $8.5 \mathrm{ppm}$, whereas that from free AuNP was merely $0.1 \mathrm{ppm}$. When the concentrations were translated into the number of NPs, assuming that the diameter of the AuNPs is $\sim 80 \mathrm{~nm}$, each cell, on average, engulfed 3579 or 42 AuNPs from the AuNPcontaining nanogels or free AuNP, respectively. The result indicates that the positively charged AuNP-containing nanogels significantly enhances the cellular uptake of AuNP-NDP by $\sim 85$-fold in comparison to free AuNP. The electrostatic interaction between the positively charged NDPMA-based nanogels and negatively charged phospholipid bilayer of cell membranes increases the internalization of the nanogels. ${ }^{31}$

2.6. Green Laser-Induced Cell Death of Nanogels. The L929 cells were incubated with NDP or $\operatorname{NDPC}_{20}(100 \mu \mathrm{g} / \mathrm{mL})$ and then irradiated by green laser. The Live/Dead staining indicated that some of the cells $(\sim 20 \%)$ incubated with NDP were killed without the illumination of green light (Figure 5A). However, the combination of green light irradiation did not further increase cell death in the presence of NDP (Figure 5B). The observation indicates that green light illumination does not damage the cells. In contrast, cell death was increased significantly in the cells incubated with $\mathrm{NDPC}_{20}$ during the green laser irradiation. After $5 \mathrm{~min}$ of exposure to a $3 \mathrm{~W}$ green laser, cell mortality increased from $\sim 25 \%$ to more than $80 \%$ (Figure 5B). The cell mortality also increased with an increasing intensity of green laser. Green laser $(5 \mathrm{~min})$ illumination caused $\sim 65$ and $\sim 80 \%$ cell death at the intensities of 1 and $3 \mathrm{~W}$, respectively (Figure 5B). Our results indicate that $\mathrm{NDPC}_{20}$ could generate heat with green laser illumination and then kill cells. 
(A)
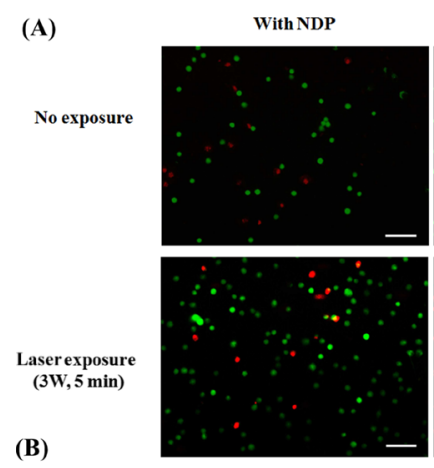

(B)

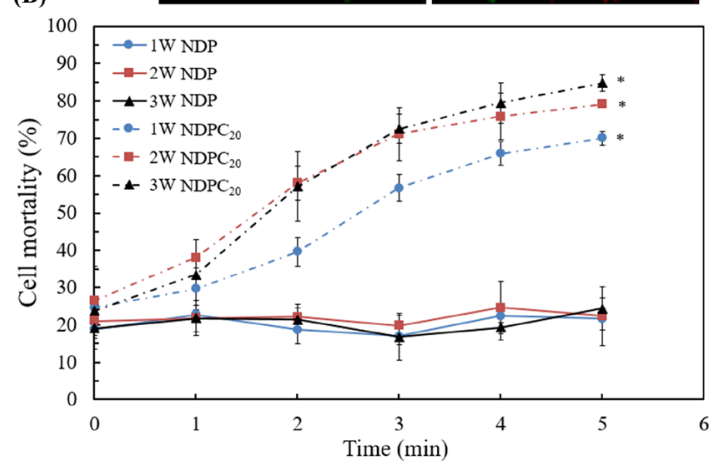

Figure 5. (A) Fluorescence images of L929 cells cultured in the culture medium with and without $\mathrm{NDPC}_{20}$ after illumination $(3 \mathrm{~W}, 5$ $\mathrm{min}$ ) or nonillumination of green laser (scale bar $=200 \mu \mathrm{m})$. (B) Green laser-induced cell death of NDP (solid line) or $\mathrm{NDPC}_{20}$ (dashed line) with different power densities and illumination times ( $n$ $=3, * p<0.001$ in comparison with the nonilluminated samples).

This study is a proof-of-concept demonstration of the cellkilling ability of endocytosed chlorophyllin-containing nanogels via the heat induced by green laser illumination. To test our concept, a positively charged nanogel was synthesized for the facilitation of cellular uptake. Although the endocytosis of NDPC is demonstrated, the intrinsic cytotoxicity of positively charged nanogels also results in the mortality of the cells. Nevertheless, the illumination of green laser greatly enhances cell mortality, suggesting the feasibility of green laser-induced thermal therapy. Furthermore, several studies indicated that cancer cells are more vulnerable to heat than normal cells. ${ }^{32}$ Thus, we propose that the nanogels containing SCC are potential candidates for hyperthermia in cancer treatment.

In the future, we will design SCC-containing nanogels to specifically target cancer cells. To decrease the nonspecific interactions of nanogels with cells and tissues, antifouling materials, ${ }^{33}$ such as polyethylene glycol (PEG) ${ }^{34}$ and zwitterionic polymers, ${ }^{35}$ would be used to synthesize nanogels. Such nanogels could avoid the undesirable endocytosis of nanogels in normal cells. Furthermore, to enhance the accumulation of nanogels at the sites of action, the nanogels could be conjugated with peptides and protein, ${ }^{36}$ galactose, ${ }^{37}$ or coated with cell membranes, ${ }^{38}$ leading to specific cell endocytosis. Therefore, chlorophyllin-containing nanogels could enter tumors with minimal damages to the normal tissues.

\section{CONCLUSIONS}

A nanogel containing SCC was successfully synthesized for potential application in photothermal therapies. Although the intrinsic positive charges of NDP-based nanogels cause cytotoxicity, the mortality of L929 cells incubated with
NDPC nanogel was enhanced by $60 \%$ after green laser exposure, whereas that with NDP was not increased by green laser illumination. We hope this work could shed light on the development of nanocarriers for photothermal clinical therapy in the future.

\section{EXPERIMENTAL SECTION}

4.1. Chemicals. NDPMA (cat. no. 409472), PEG diacrylate (PEGDA, cat. no. 455008), ammonium persulfate (APS, cat. no. A3678), chlorophyllin sodium copper salt (SCC, cat. no. C6003), Span80 (cat. no. S6760), trypsin-ethylenediaminetetraacetic acid (cat. no. T4174), nitric acid (cat. no. 438073), fetal bovine serum (FBS, cat. no. T8153), 2mercaptoethanol (cat. no. M3148), and trypan blue (cat. no. T8154) were purchased from Sigma-Aldrich (St. Louis, USA). Live/Dead cell imaging kit, alpha minimum essential medium ( $\alpha$-MEM, cat. no.11900-024), and gentamicin (cat. no. 15710064) were purchased from Thermo Fisher Scientific (Waltham, USA). CellTiter $96 \mathrm{AQ}_{\text {neous }}$ One Solution Reagent (for MTS assay; cat. no. G3580) was purchased from Promega (Fitchburg, USA). L929 fibroblasts were obtained from Food Industry Research and Development Institute (Hsinchu, Taiwan). The cell culture medium was composed of $90 \% \alpha$ MEM and 10\% FBS (Biological Industries, Israel), supplemented with $2 \mathrm{mg} / \mathrm{mL}$ of $\mathrm{NaHCO}_{3}, 0.5 \%$ of fungizone (GIBCO, USA), $0.25 \%$ gentamicin, and $0.679 \% \beta$-mercaptoethanol. The AuNPs, which were synthesized based on a previous method, ${ }^{39}$ were kindly provided by Professor ShiaoWen Tsai at Chang Gung University, Taoyuan city, Taiwan.

4.2. Synthesis and Purification of Nanogels. Two types of nanogels, NDP and NDPC, were synthesized via inverse miniemulsion polymerization in a water-in-oil system, as described previously. ${ }^{40}$ NDPMA $(80 \mathrm{mg}), 10 \mathrm{mg}$ PEGDA, and $10 \mathrm{mg}$ APS were dissolved in $3 \mathrm{~mL}$ of deionized (DI) water. The monomer solution was mixed with $20 \mathrm{~mL}$ of hexane containing $1 \mathrm{~g}$ Span 80 and then sealed in a glass tube. The reaction mixture was purged with nitrogen for $30 \mathrm{~min}$ and then sonicated for $5 \mathrm{~min}$ to form small micelles. Polymerization of the monomers was initiated at $60{ }^{\circ} \mathrm{C}$ and proceeded for $2 \mathrm{~h}$. For the synthesis of NDPC, 7 or $21 \mathrm{mg}$ SCC was added in the monomer solution prior to the mixing with the Span 80 solution. After the reaction, the detergent was removed by the addition of $5 \mathrm{~mL}$ of acetone into the reaction mixture, followed by centrifugation at $14,000 \mathrm{rpm}$ for $20 \mathrm{~min}$. The precipitate was further dispersed in a mixture of $30 \mathrm{~mL}$ of hexane $/ 5 \mathrm{~mL}$ of acetone and then centrifuged at $14,000 \mathrm{rpm}$ for $20 \mathrm{~min}$ two times for further removal of the residual detergent. The precipitate was suspended in DI water and then filtered through 0.45 and $0.22 \mu \mathrm{m}$ syringe filters sequentially. The product was dialyzed against DI water and lyophilized. The nanogels were stored at $4{ }^{\circ} \mathrm{C}$ before use.

4.3. Characterization of the Nanogels. The size distribution and surface charge of the nanogels were analyzed by a Zetasizer Nano ZS DLS instrument (Malvern, U.K.) at room temperature. The amount of SCC in NDPC was quantified using a UV-visible spectroscope (CARY 100nc, Agilent, USA). Briefly, $1 \mathrm{mg}$ of nanogels was dispersed in $1 \mathrm{~mL}$ of DI water by $20 \mathrm{~min}$ of sonication, and then the absorbance at $405 \mathrm{~nm}$ was measured. The SCC content of NDPC was determined according to a standard curve obtained from the absorbance of SCC solutions with known concentrations. ${ }^{1} \mathrm{H}$ NMR experiments were performed on a Bruker ADVANCE$500 \mathrm{MHz}$ FT NMR spectrometer $(500 \mathrm{MHz})$ using $\mathrm{D}_{2} \mathrm{O}$ as 
the solvent $(1 \mathrm{mg} / \mathrm{mL})$ at ambient temperature, and tetramethyl silane was used as the internal standard. The copper ion concentration was determined from the dissolved nanogels in DI water and analyzed using ICP-AES (Optima 8000, PerkinElmer, USA).

The AuNPs were incorporated into the nanogels through vigorous mixing. ${ }^{39}$ Briefly, AuNP-NDP complexes were prepared by stirring a solution of AuNPs (100 ppm) and NDP $(0.9 \mathrm{mg} / \mathrm{mL})$ vigorously for 4 days, followed by dialysis against DI water for 2 days, and then freeze-drying. The incorporation of AuNPs in the complexes was demonstrated via TEM imaging.

4.4. Cytotoxicity of SCC and Nanogels. The L929 cells were seeded on a 96-well plate at a density of $2 \times 10^{4}$ cells $/ \mathrm{cm}^{2}$ and cultured for $24 \mathrm{~h}$. The culture medium was then replaced by a culture medium containing various amounts of nanogels or SCC for 2 or $24 \mathrm{~h}$, respectively. The cell viability was evaluated using an MTS assay. A fresh culture medium was used as the negative control, whereas the medium supplemented with $0.5 \%$ phenol was used as the positive control. The solution in each well was replaced by $100 \mu \mathrm{L}$ of fresh medium and $20 \mu \mathrm{L}$ of MTS reagents. After $3 \mathrm{~h}$ of incubation, the absorbance of the solution was determined at $570 \mathrm{~nm}\left(\mathrm{OD}_{570}\right)$ and $630 \mathrm{~nm}\left(\mathrm{OD}_{630}\right)$ using an ELISA reader (Model EL800, BIO-TEK, USA). The relative cell viability was calculated using the following equation

$$
\text { Relative cell viability }=\frac{\left(\mathrm{OD}_{570}-\mathrm{OD}_{630}\right)_{\text {sample }}}{\left(\mathrm{OD}_{570}-\mathrm{OD}_{630}\right)_{\text {medium }}} \times 100 \%
$$

4.5. Photothermal Properties of the Nanogels. The nanogel solutions in the cell culture medium $(100 \mu \mathrm{g} / \mathrm{mL})$ were illuminated with a green laser at $532 \mathrm{~nm}$ wavelength (Class IV laser product, Changchun New Industries Optoelectronics Tech. Co., Ltd., China). A thermocouple (1 mm in diameter) was inserted into the center of a $1 \mathrm{~mL}$ nanogel solution, and the temperature was measured before and immediately after green laser illumination.

4.6. Determination of Cellular Uptake of the Nanogels. To evaluate the cellular uptake of the nanogels, the L929 cells, precultured in a culture dish to almost confluence, were fed with $0.1 \mathrm{mg} / \mathrm{mL}$ of either NDPC or Au-incorporated NDPC. The contents of the copper ions chelated in SCC and of the AuNPs embedded in NDP nanogels were quantified by ICP-AES (Optima 8000, PerkinElmer, USA). After $2 \mathrm{~h}$ of incubation, the cells were rinsed with phosphate-buffered saline (PBS) and harvested from the dish. For copper quantification, the cells were dispersed in DI water, sonicated for several hours, and then filtered through a $0.45 \mu \mathrm{m}$ syringe filter. For gold quantification, the cells were digested by $10 \mathrm{M}$ aqua regia (a mixture of nitric acid and hydrochloric acid in a molar ratio of $1: 3)$ for $2 \mathrm{~h}$. Then, the contents of $\mathrm{Cu}$ or $\mathrm{Au}$ in the sample solutions were analyzed using ICP-AES.

4.7. Mortality of L929 Cells Treated with the Nanogels under Green Laser Illumination. The L929 cells were cultured on 24-well plates until almost confluence. The culture medium was replaced by a nanogel-containing culture medium $(100 \mu \mathrm{g}$ nanogel $/ \mathrm{mL})$ and then incubated for $2 \mathrm{~h}$. The samples were then rinsed with PBS twice to remove the free nanogels. The samples were then irradiated with green laser at various intensities $\left(1,2\right.$, or $\left.3 \mathrm{~W} / \mathrm{cm}^{2}\right)$ and illumination times (1-5 $\mathrm{min})$. After the green laser illumination, the cell mortality was examined via MTS assay and Live/Dead staining. For Live/Dead staining, the samples were incubated with the Live/Dead cell-imaging solution according to the manufacturer's instructions and then observed using a fluorescent microscope (Eclipse 80i microscope, Nikon, Japan).

4.8. Statistical Analysis. The statistical analyses between different groups were calculated by the Student-Keuls Multiple Comparisons Test (Instat 3.0, GraphPad Software, USA). A probability of $p \leq 0.05$ was considered a significant difference.

\section{ASSOCIATED CONTENT}

\section{Supporting Information}

The Supporting Information is available free of charge on the ACS Publications website at DOI: 10.1021/acsomega.8b01689.

${ }^{1} \mathrm{H}$ NMR spectra of NDP, NDPC $10, \mathrm{NDPC}_{20}$, and SCC; calibration curve of SCC with different concentrations; TEM image of the AuNP-NDP nanogel; and DLS analysis of the AuNP-contained nanogels (PDF)

\section{AUTHOR INFORMATION}

\section{Corresponding Author}

*E-mail: weibortsai@ntu.edu.tw. Phone: +886-2-3366-3996. ORCID

Wei-Bor Tsai: 0000-0002-2316-5751

\section{Notes}

The authors declare no competing financial interest.

\section{ACKNOWLEDGMENTS}

This work was financially supported by the Advanced Research Center of Green Materials Science and Technology from The Featured Area Research Center Program within the framework of the Higher Education Sprout Project by the Ministry of Education (107L9006) and the Ministry of Science and Technology in Taiwan (MOST 105-2923-E-002-017-MY2). The authors are grateful to the staff of Technology Commons, College of Life Science, at National Taiwan University for the help with TEM.

\section{REFERENCES}

(1) Siegel, R. L.; Miller, K. D.; Jemal, A. Cancer statistics, 2018. CaCancer J. Clin. 2018, 68, 7-30.

(2) Liu, Y.; Ai, K.; Liu, J.; Deng, M.; He, Y.; Lu, L. Dopaminemelanin colloidal nanospheres: an efficient near-infrared photothermal therapeutic agent for in vivo cancer therapy. Adv. Mater. 2013, $25,1353-1359$.

(3) Sun, J.; Guo, M.; Pang, H.; Qi, J.; Zhang, J.; Ge, Y. Treatment of malignant glioma using hyperthermia. Neural Regener. Res. 2013, 8, $2775-2782$.

(4) Kennedy, L. C.; Bickford, L. R.; Lewinski, N. A.; Coughlin, A. J.; Hu, Y.; Day, E. S.; West, J. L.; Drezek, R. A. A New Era for Cancer Treatment: Gold-Nanoparticle-Mediated Thermal Therapies. Small 2011, 7, 169-183.

(5) Short, J. G.; Turner, P. F. Physical hyperthermia and cancer therapy. Proc. IEEE 1980, 68, 133-142.

(6) Krishnan, S.; Diagaradjane, P.; Cho, S. H. Nanoparticlemediated thermal therapy: Evolving strategies for prostate cancer therapy. Int. J. Hyperthermia 2010, 26, 775-789.

(7) Shanmugam, V.; Selvakumar, S.; Yeh, C.-S. Near-infrared lightresponsive nanomaterials in cancer therapeutics. Chem. Soc. Rev. 2014, $43,6254-6287$. 
(8) Molina, M.; Asadian-Birjand, M.; Balach, J.; Bergueiro, J.; Miceli, E.; Calderón, M. Stimuli-responsive nanogel composites and their application in nanomedicine. Chem. Soc. Rev. 2015, 44, 6161-6186.

(9) Ekkelenkamp, A. E.; Elzes, M. R.; Engbersen, J. F. J.; Paulusse, J. M. J. Responsive crosslinked polymer nanogels for imaging and therapeutics delivery. J. Mater. Chem. B 2018, 6, 210-235.

(10) Deshpande, S.; Sharma, S.; Koul, V.; Singh, N. Core-Shell Nanoparticles as an Efficient, Sustained, and Triggered Drug-Delivery System. ACS Omega 2017, 2, 6455-6463.

(11) Li, F.; Yang, H.; Bie, N.; Xu, Q.; Yong, T.; Wang, Q.; Gan, L.; Yang, X. Zwitterionic Temperature/Redox-Sensitive Nanogels for Near-Infrared Light-Triggered Synergistic Thermo-Chemotherapy. ACS Appl. Mater. Interfaces 2017, 9, 23564-23573.

(12) Wang, H.; Mukherjee, S.; Yi, J.; Banerjee, P.; Chen, Q.; Zhou, S. Biocompatible Chitosan-Carbon Dot Hybrid Nanogels for NIRImaging-Guided Synergistic Photothermal-Chemo Therapy. ACS Appl. Mater. Interfaces 2017, 9, 18639-18649.

(13) Tian, Z.; Yao, X.; Ma, K.; Niu, X.; Grothe, J.; Xu, Q.; Liu, L.; Kaskel, S.; Zhu, Y. Metal-Organic Framework/Graphene Quantum Dot Nanoparticles Used for Synergistic Chemo- and Photothermal Therapy. ACS Omega 2017, 2, 1249-1258.

(14) Müller, G. J.; Berlien, P.; Scholz, C. The medical laser. Laser Med. Sci. 2006, 21, 99-108.

(15) Pegau, W. S.; Gray, D.; Zaneveld, J. R. V. Absorption and attenuation of visible and near-infrared light in water: dependence on temperature and salinity. Appl. Opt. 1997, 36, 6035-6046.

(16) Azadgoli, B.; Baker, R. Y. Laser applications in surgery. Ann. Transl. Med. 2016, 4, 452 .

(17) Zhang, X.; Shen, P.; He, Q.; Yin, X.; Chen, Z.; Gui, H.; Shu, K.; Tang, Q.; Yang, Y.; Pan, X.; Wang, J.; Chen, N.; Zeng, H. Different lasers in the treatment of benign prostatic hyperplasia: a network meta-analysis. Sci. Rep. 2016, 6, 23503.

(18) Bressler, S. B.; Almukhtar, T.; Aiello, L. P.; Bressler, N. M.; Ferris, F. L.; Glassman, A. R.; Greven, C. M. Green or Yellow Laser Treatment for Diabetic Macular Edema: Exploratory Assessment within the Diabetic Retinopathy Clinical Research Network. Retina 2013, 33, 2080.

(19) Liu, X.; Shan, G.; Yu, J.; Yang, W.; Ren, Z.; Wang, X.; Xie, X.; Chen, H.-j.; Chen, X. Laser heating of metallic nanoparticles for photothermal ablation applications. AIP Adv. 2017, 7, 025308.

(20) Mendes, R.; Pedrosa, P.; Lima, J. C.; Fernandes, A. R.; Baptista, P. V. Photothermal enhancement of chemotherapy in breast cancer by visible irradiation of Gold Nanoparticles. Sci. Rep. 2017, 7, 10872.

(21) AL-Jawad, S. M. H.; Taha, A. A.; Al-Halbosiy, M. M. F.; ALBarram, L. F. A. Synthesis and characterization of small-sized gold nanoparticles coated by bovine serum albumin (BSA) for cancer photothermal therapy. Photodiagn. Photodyn. Ther. 2018, 21, 201210.

(22) Gomes, B. B.; Barros, S. B. M.; Andrade-Wartha, E. R. S.; Silva, A. M. O.; Silva, V. V.; Lanfer-Marquez, U. M. Bioavailability of dietary sodium copper chlorophyllin and its effect on antioxidant defence parameters of Wistar rats. J. Sci. Food Agric. 2009, 89, 2003-2010.

(23) Li, B.; Wu, Z.; Li, W.; Jia, G.; Lu, J.; Fang, J.; Chen, G. Chlorophyllin e4 is a novel photosensitizer against human bladder cancer cells. Oncol. Rep. 2012, 27, 1455-1460.

(24) Chang, C.; Dan, H.; Zhang, L.-P.; Chang, M.-X.; Sheng, Y.-F.; Zheng, G.-H.; Zhang, X.-Z. Fabrication of thermoresponsive, corecrosslinked micelles based on poly[ $\mathrm{N}$-isopropyl acrylamide-co-3(trimethoxysilyl)propylmethacrylate]-b-poly\{N-[3-(dimethylamino)propyl]methacrylamide $\}$ for the codelivery of doxorubicin and nucleic acid. J. Appl. Polym. Sci. 2015, 132, 41752-41761.

(25) Aachmann, F. L.; Sorlie, M.; Skjak-Braek, G.; Eijsink, V. G. H.; Vaaje-Kolstad, G. NMR structure of a lytic polysaccharide monooxygenase provides insight into copper binding, protein dynamics, and substrate interactions. Proc. Natl. Acad. Sci. U.S.A 2012, 109, 18779-18784.

(26) Peana, M. F.; Medici, S.; Ledda, A.; Nurchi, V. M.; Zoroddu, M. A. Interaction of $\mathrm{Cu}(\mathrm{II})$ and $\mathrm{Ni}(\mathrm{II})$ with Ypk9 Protein Fragment via NMR Studies. Sci. World J. 2014, 2014, 1.
(27) Tang, M.; Mao, K.; Li, S.; Zhuang, J.; Diallo, K. Paramagnetic effects on the NMR spectra of isotropic bicelles with headgroup modified chelator lipids and metal ions. Phys. Chem. Chem. Phys. 2016, 18, 15524-15527.

(28) York, A. W.; Zhang, Y.; Holley, A. C.; Guo, Y.; Huang, F.; McCormick, C. L. Facile Synthesis of Multivalent Folate-Block Copolymer Conjugates via Aqueous RAFT Polymerization: Targeted Delivery of siRNA and Subsequent Gene Suppression. Biomacromolecules 2009, 10, 936-943.

(29) Tiranti, V.; Hoertnagel, K.; Carrozzo, R.; Galimberti, C.; Munaro, M.; Granatiero, M.; Zelante, L.; Gasparini, P.; Marzella, R.; Rocchi, M.; Bayona-Bafaluy, M. P.; Enriquez, J.-A.; Uziel, G.; Bertini, E.; Dionisi-Vici, C.; Franco, B.; Meitinger, T.; Zeviani, M. Mutations of SURF-1 in Leigh Disease Associated with Cytochrome c Oxidase Deficiency. Am. J. Hum. Genet. 1998, 63, 1609-1621.

(30) Williams, S. L.; Valnot, I.; Rustin, P.; Taanman, J.-W. Cytochrome c Oxidase Subassemblies in Fibroblast Cultures from Patients Carrying Mutations in COX10, SCO1, or SURF1. J. Biol. Chem. 2004, 279, 7462-7469.

(31) Fröhlich, E. The role of surface charge in cellular uptake and cytotoxicity of medical nanoparticles. Int. J. Nanomed. 2012, 7, 55775591.

(32) Storm, F. K.; Harrison, W. H.; Elliott, R. S.; Morton, D. L. Normal Tissue and Solid Tumor Effects of Hyperthermia in Animal Models and Clinical Trials. Cancer Res. 1979, 39, 2245-2251.

(33) Lowe, S.; O’Brien-Simpson, N. M.; Connal, L. A. Antibiofouling polymer interfaces: poly(ethylene glycol) and other promising candidates. Polym. Chem. 2015, 6, 198-212.

(34) Grossen, P.; Witzigmann, D.; Sieber, S.; Huwyler, J. PEG-PCLbased nanomedicines: A biodegradable drug delivery system and its application. J. Controlled Release 2017, 260, 46-60.

(35) Miller, J. B.; Zhang, S.; Kos, P.; Xiong, H.; Zhou, K.; Perelman, S. S.; Zhu, H.; Siegwart, D. J. Non-Viral CRISPR/Cas Gene Editing In Vitro and In Vivo Enabled by Synthetic Nanoparticle Co-Delivery of Cas9 mRNA and sgRNA. Angew. Chem., Int. Ed. Engl. 2017, 56, 1059-1063.

(36) Spicer, C. D.; Jumeaux, C.; Gupta, B.; Stevens, M. M. Peptide and protein nanoparticle conjugates: versatile platforms for biomedical applications. Chem. Soc. Rev. 2018, 47, 3574-3620.

(37) Jain, A.; Jain, A.; Parajuli, P.; Mishra, V.; Ghoshal, G.; Singh, B.; Shivhare, U. S.; Katare, O. P.; Kesharwani, P. Recent advances in galactose-engineered nanocarriers for the site-specific delivery of siRNA and anticancer drugs. Drug Discov. Today 2018, 23, 960-973.

(38) Fang, R. H.; Kroll, A. V.; Gao, W.; Zhang, L. Cell Membrane Coating Nanotechnology. Adv. Mater. 2018, 30, 1706759.

(39) Khan, A.; Alhoshan, M. Preparation and characterization of pHresponsive and thermoresponsive hybrid microgel particles with gold nanorods. J. Polym. Sci., Part A: Polym. Chem. 2013, 51, 39-46.

(40) Sarika, P. R.; James, N. R. Preparation and characterisation of gelatin-gum arabic aldehyde nanogels via inverse miniemulsion technique. Int. J. Biol. Macromol. 2015, 76, 181-187. 